\title{
LYMPHOCYTOSIS AFTER ELECTRICAL CONVULSION
}

BY

\section{JOSHUA CARSE and ELIOT SLATER}

\author{
(ReCeIved 13Th SEPTEMBER, 1945)
}

\section{Introduction}

Several authors have reported changes in white cell count after artificially induced convulsionsFattovich (1937, 1938), Blomquist (1938), Lemmi (1939); Horn (1939), Felici (1940). Unfortunately only two of these papers are accessible to us. The first paper of Fattovich is a very brief communication, unsupported by case records or figures, in which he states that within the first half-hour after cardiazol shock in the schizophrenic there is an increase in the monocytes, a diminution of neutrophils, and in some cases a slight diminution in lymphocytes; later on there is an increase in neutrophils, and a diminution of lymphocytes, and eosinophils. Horn discusses his results with azoman, cardiazol and neospiran on 10 schizophrenics, and quotes in tabular form the findings made with six of them. His readings are made at time 0 and after 1 and 2 hours. He finds diminution of basophils, eosinophils, and lymphocytes, no change in the monocytes, and big increases in neutrophils, especially immature forms. He attributes these changes not to the drugs, but to autonomic stimulation by the convulsion. In support of his views he quotes the observations of Georgi and Wechsler on the blood picture in insulin shock. Blomquist and Lemmi report their findings with metrazol, and Felici his with electrical shock; it is to be regretted that the war has made these papers inaccessible.

The investigation that is described below was carried out by one of us (J. C.) without the knowledge of the work of these authors, and was begun in 1937. It was thought desirable to record the findings within a few minutes of the convulsion, and the following technique was used. The laboratory technician was present in the theatre before treatment was begun, and actual and differential cell counts were made on the fasting patient. Throughout the tests capillary blood from the finger-tip was used, and for every count 200 white cells were counted. The time at which the electrical convulsion was given was noted and cell counts were made at intervals of 3 minutes for the first hour and again at $1 \frac{1}{2}$ and 2 hours. In the series of 50 patients under consideration in this paper, however, counts were only made at 3-minute intervals for 21 minutes, and at 30, 45, and 60 minutes, as most of the more remarkable changes were observed in the first quarter of an hour.

\section{Results}

Immediately after the convulsion, during the next 15 minutes, there are violent fluctuations in the number of neutrophils. In one of the 50 patients observed there was a rise in their number from 3,600 at time 0 to 10,300 at 6 minutes. But it is almost as common for the number of neutrophils to drop as to rise; one of the patients showed at time 03,400 neutrophils; at 3 minutes after the convulsion 1,800; at 6 minutes 3,500 ; and at 9 minutes 6,700. The fluctuations are rapid and entirely irregular. When mean values of the 50 observations at every time interval are calculated no consistent rise or fall is found; and analysis of variance shows that such differences as are seen are not significant. There is, however, a highly significant rise in the standard deviation of the observations from 574 at 0 minutes to an almost threefold value of 1,692 at 6 minutes, corresponding to the greatly increased range of individual variation. Furthermore there is a significant tendency for the females to score on the average higher values than the males.

It is otherwise with the lymphocytes. Although these also fluctuate sharply after the convulsion, there is a systematic tendency for their number to rise to a maximum at the sixth minute, and thereafter to decline more gradually back towards the norm. Analysis permits of no doubt that this tendency is a meaningful one, and not to be accounted for by experimental error or by random variance from other causes.

In view of the interest of this finding, it was thought desirable to test for differences in the degree of lymphocytosis when patients were subclassified by sex and diagnosis. Of the 50 patients 30 were schizophrenic or paraphrenic, 15 male and 15 female, and 20 suffered from other mental disorders predominantly involutional melancholia, 9 male and 11 female. The results of the subclassification are given in Table I. It will be noted that in males the rise in number of lymphocytes is more marked than in females, and that it is more marked in the schizophrenics than in the others. The significance of all these findings was tested by analysis of 
TABLE I

\begin{tabular}{|c|c|c|c|c|c|c|c|c|}
\hline \multirow{4}{*}{$\begin{array}{c}\text { Time } \\
\text { (minutes) }\end{array}$} & \multicolumn{8}{|c|}{ Mean number of white cells per cubic millimetre } \\
\hline & \multicolumn{3}{|c|}{ Neutrophils } & \multicolumn{5}{|c|}{ Lymphocytes } \\
\hline & \multirow{2}{*}{$\begin{array}{c}\text { All } \\
\text { groups }\end{array}$} & \multirow{2}{*}{ Male } & \multirow{2}{*}{ Female } & \multirow{2}{*}{$\begin{array}{c}\text { All } \\
\text { groups }\end{array}$} & \multicolumn{2}{|c|}{ Schizophrenics } & \multicolumn{2}{|c|}{ Others } \\
\hline & & & & & Male & Female & Male & Female \\
\hline $\begin{array}{r}0 \\
3 \\
6 \\
9 \\
12 \\
15 \\
18 \\
21 \\
30 \\
45 \\
60\end{array}$ & $\begin{array}{l}3,590 \\
3,450 \\
3,700 \\
3,650 \\
3,360 \\
3,710 \\
3,540 \\
3,440 \\
3,540 \\
3,620 \\
3,610\end{array}$ & $\begin{array}{l}3,440 \\
3,260 \\
3,500 \\
3,560 \\
3,130 \\
3,350 \\
3,380 \\
3,360 \\
3,570 \\
3,490 \\
3,510\end{array}$ & $\begin{array}{l}3,730 \\
3,630 \\
3,880 \\
3,730 \\
3,570 \\
4,040 \\
3,690 \\
3,520 \\
3,510 \\
3,740 \\
3,700\end{array}$ & $\begin{array}{l}1,420 \\
2,050 \\
2,600 \\
2,350 \\
1,910 \\
1,890 \\
1,590 \\
1,570 \\
1,450 \\
1,470 \\
1,440\end{array}$ & $\begin{array}{l}1,430 \\
2,130 \\
2,840 \\
2,910 \\
2,210 \\
2,230 \\
1,830 \\
1,860 \\
1,570 \\
1,490 \\
1,490\end{array}$ & $\begin{array}{l}1,470 \\
2,050 \\
2,690 \\
2,030 \\
2,000 \\
1,830 \\
1,480 \\
1,550 \\
1,580 \\
1,550 \\
1,580\end{array}$ & $\begin{array}{l}1,440 \\
2,090 \\
2,700 \\
2,050 \\
1,620 \\
1,980 \\
1,470 \\
1,650 \\
1,430 \\
1,390 \\
1,310\end{array}$ & $\begin{array}{l}1,310 \\
1,840 \\
2,040 \\
2,200 \\
1,600 \\
1,390 \\
1,360 \\
1,290 \\
1,120 \\
1,380 \\
1,360\end{array}$ \\
\hline
\end{tabular}

Capillary white cell counts at stated number of minutes after electrical convulsion.

TABLE II

\begin{tabular}{|c|c|c|c|c|c|}
\hline \multirow{2}{*}{ Source of variance } & & \multicolumn{2}{|c|}{ Neutrophils: } & \multicolumn{2}{|c|}{ Lymphoctyes: } \\
\hline & $\begin{array}{l}\text { Degrees } \\
\text { freedom }\end{array}$ & $\begin{array}{l}\text { Sum of } \\
\text { squares }\end{array}$ & $\mathbf{P}$ & $\begin{array}{l}\text { Sum of } \\
\text { squares }\end{array}$ & $P \quad \stackrel{Q}{2}$ \\
\hline 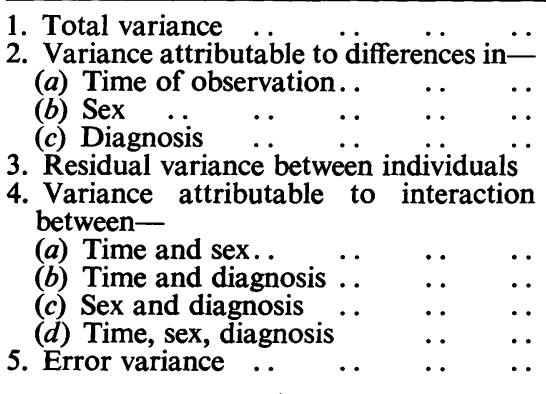 & $\begin{array}{r}527 \\
10 \\
1 \\
1 \\
44\end{array}$ & \begin{tabular}{r|}
$54843 \cdot 62$ \\
$669 \cdot 47$ \\
$1251 \cdot 84$ \\
$0 \cdot 63$ \\
$25159 \cdot 14$ \\
\\
\\
$525 \cdot 10$ \\
$548 \cdot 62$ \\
$84 \cdot 28$ \\
$1031 \cdot 18$ \\
$25573 \cdot 36$
\end{tabular} & $\begin{array}{l}>0.05 \\
<0.001 \\
>0.05 \\
<0.01 \\
\\
>0.05 \\
>0.05 \\
>0.05 \\
>0.05\end{array}$ & \begin{tabular}{r|}
$29334 \cdot 91$ \\
$8055 \cdot 47$ \\
$413 \cdot 05$ \\
$653 \cdot 49$ \\
$5161 \cdot 89$ \\
\\
\\
$340 \cdot 77$ \\
210.09 \\
0.30 \\
$672 \cdot 50$ \\
$13827 \cdot 35$
\end{tabular} & $\begin{array}{l}<0.001 \stackrel{\bar{Q}}{\rightleftharpoons} \\
<0.001 \\
<0.001 \\
<0.001 \\
\\
>0.05 \\
>0.05 \\
>0.05 \\
<0.05\end{array}$ \\
\hline
\end{tabular}

Analysis of variance. Probability (P) is ascertained from the variance ratio, F. For this analysis two female non-schizophrenic patients, chosen at random, were omitted, in order to make the numerical relationships orthogonal, when the patients were subclassified by diagnosis and sex.

variance, the mode of collection of the data permitting this to be carried out with an unusual degree of completeness (Table II). The analysis establishes the statistical significance of all three findings-the occurrence of a lymphocytosis, and of sex and diagnostic differences.*

As perhaps might have been expected, in view of the findings, neutrophil and lymphocyte counts were only very loosely correlated. The correlation coefficient has a small but significant value of $+\cdot 10(\mathrm{P}<\cdot 02)$.

\section{Discussion}

We do not wish to enter into a theoretical discussion of these findings. According to Wiggers * The effects of age had also to be taken into account. The mean
age of the schizophrenics, male and female, was 33 years, range
$15-55$, and of the non-schizophrenics, both male and female, was
52 , range $26-70$. The regression of lymphocyte count on age, dia-
gnosis held constant, was calculated but found to be non-significant.
(1944), a neutrophil leucocytosis is well known after convulsive seizures, hard exercise, and severe pain, the changes being attributed to release of leucocytes trapped in unused capillaries, especially in the lungs and liver. Lymphocytosis, when it occurs, is attributed to an increased flow of lymph; it is produced in adults by actinic radiation, exposure of lymph nodes to X-rays, the effect of dry heat and high altitudes. It is difficult to see how mechanisms operative in these circumstances should also be the ones involved after electrical convulsion. We would agree with Horn in attributing the leucocyte changes in general to a disturbance of central regulation of the autonomic system. A point of great interest is that the lymphocytosis is significantly greater in the schizophrenic patients. Further discussion of this would require an advance in our knowledge of the physiology of schizophrenia. 

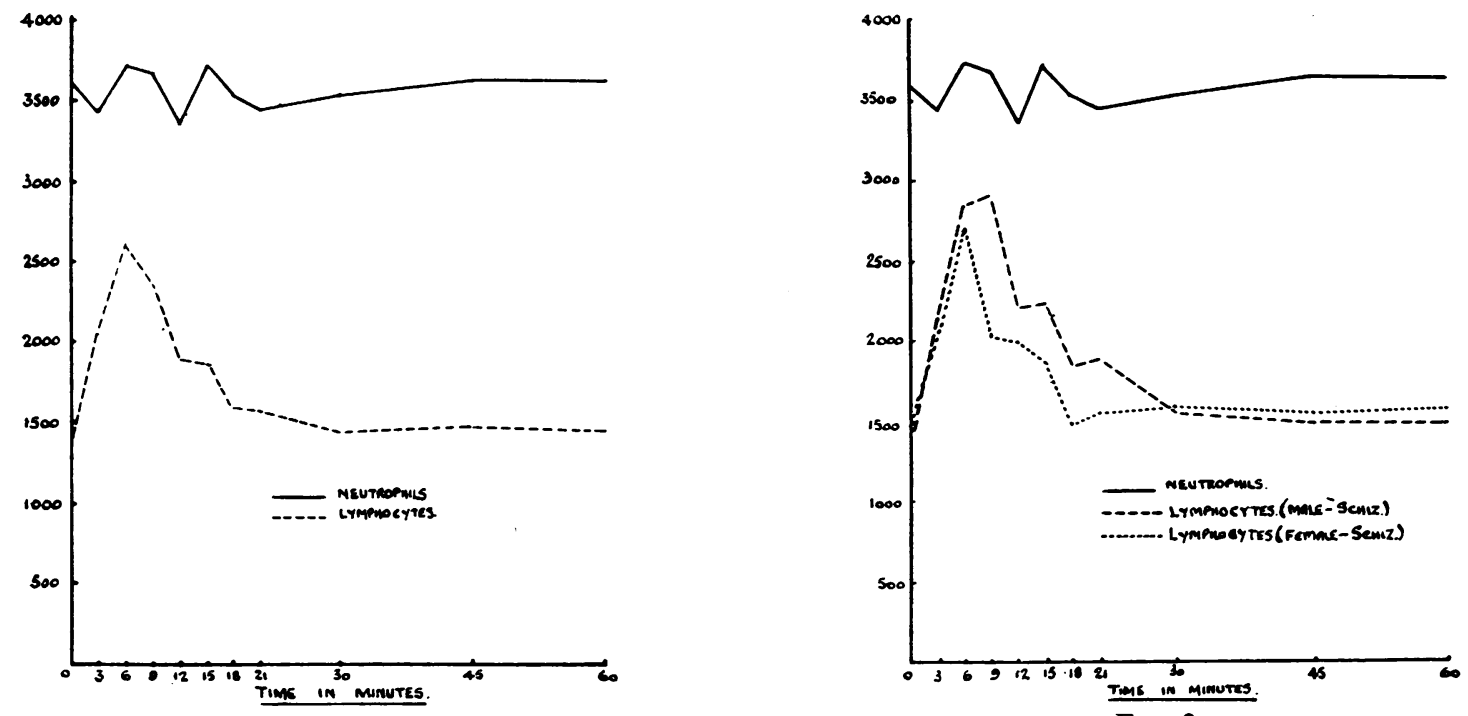

Fig. 1.

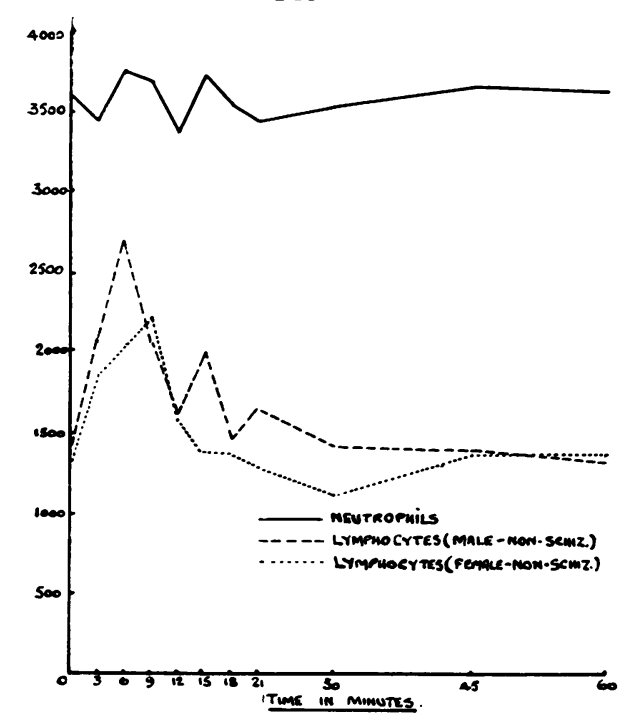

FIG. 2.

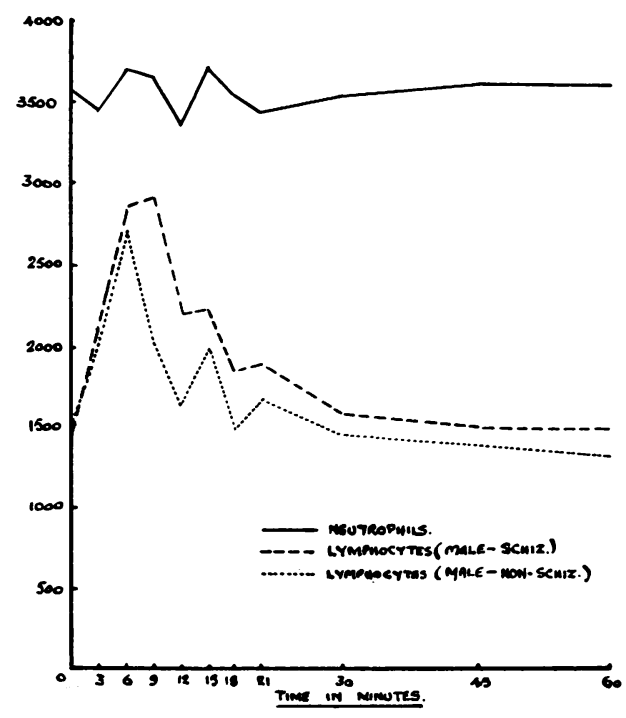

FIG. 3.

FIG. 4.

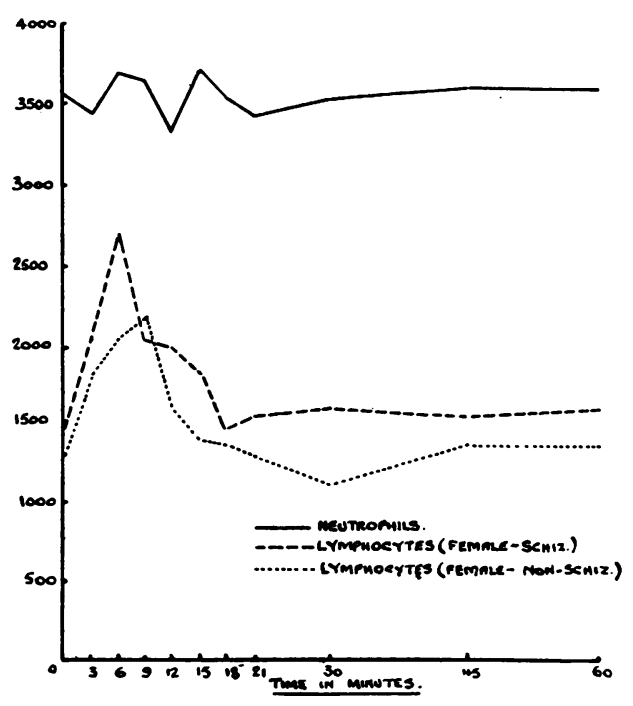

FIG. 5. 
Our finding adds but one to the increasing list of rise or fall. There is a systematic rise in the number functional disturbances that have been found in this disease. According to Hoskins (1945), schizophrenics show among other things differences from the normal in the regulation of body temperature, blood pressure, oxygen, and glutathione metabolism, reaction to insulin and to sugar. It is impossible as yet to build these manifold jig-saw pieces into a coherent picture.

\section{Summary}

After electrical convulsion there are in the first 15 minutes sharp fluctuations in the number of neutrophil leucocytes, which show no systematic of lymphocytes in the same time, greater in males $Z$ than in females, and in schizophrenic than in nonschizophrenic patients.

\section{REFERENCES}

Blomquist, J. (1938). Bull. Meninger Clinic, 2, 188. Fattovich, G. (1937). Riv. sper. Freniat., 61, 1097.

- (1938). Schizofrenie, 7, 69.

Felici, M. (1940). Riv. sper. Freniat., 64, 513.

Horn, W. (1939). Psychiat. neurol. Wschr., 41, 513.

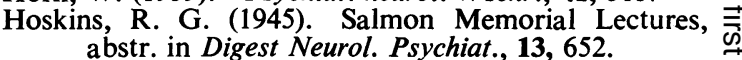

Lemmi, F. (1939). Cervello, 18, 164.
Wiggers, C. J. (1944). Physiology in Health and Disease, London, p. 314. 